\title{
THE UNIVERSITY AS A SITE FOR TRANSFORMATION: DEVELOPING CIVIC- MINDED GRADUATES AT SOUTH AFRICAN INSTITUTIONS THROUGH AN EPISTEMIC SHIFT IN INSTITUTIONAL CULTURE
}

\author{
Sharli Anne Paphitis \\ Rhodes University \\ Email: s.paphitis@ru.ac.za

\section{Lindsay Kelland} \\ Rhodes University \\ Email: I.kelland@ru.ac.za
}

\section{ABSTRACT}

At least one of the goals of the transformation of universities in South Africa is to develop civic-minded graduates who leave university to become agents of positive social change in broader society. More specifically, universities in South Africa aim to develop graduates who are critical, capable and balanced - graduates who are aware of their social responsibilities in post-apartheid South Africa. In this paper we, first, consider why South African universities should want to promote the development of socially-responsive civic-minded agents. Second, we analyse three plausible suggestions for the transformation of universities into sites that could increase a university's ability to foster civic-minded graduates on its campus: transformation of the university structures and demographics; the implementation of transformative teaching and learning practices; and the implementation of community engagement programmes. While all three of these suggestions are found to be plausible, we argue that in order for universities to become sites for transformation par excellence - sites which foster the development of civicmindedness - universities must embrace an epistemic shift in institutional culture.

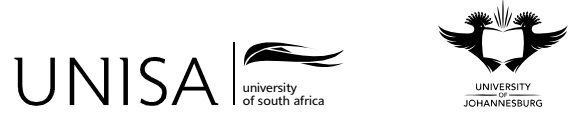


Finally, we examine some plausible causes that could be preventing this from taking place in our context.

Keywords: Transformative learning; service-learning; civic-minded graduates; community engagement; university; epistemology; institutional culture

\section{INTRODUCTION}

This paper centres on the question of how universities in South Africa might fulfil the goal of fostering graduates with a proper understanding of their socio-historic and economic context, and in light of this understanding display an enhanced sense of civic responsibility in their lives upon leaving university. When graduates truly understand their context, they are better able to respond to that context and this should, we think, empower them not only to fulfil their civic duties, but to actively and critically exercise their citizenship in responsible and transformative ways upon leaving university. But what would a university have to do in order to achieve this goal? In this paper we suggest that universities must become spaces for transformation, rather than merely being transformed spaces. It is the transformative process, through which students come to properly understand social justice that ensures students will go on to promote social justice in broader society. While universities have long been sites for personal growth and transformation in their students, the significance of the transformative power of these sites, and the important transformational goal of producing graduates who are engaged citizens working for social justice, has to some extent been overlooked in the literature on transformation at universities in South Africa.

At the outset we should mention that there might be those who remain sceptical that higher education institutions should be seen as social institutions that work for the public good, and should therefore concern themselves with promoting the development of civic-minded graduates. For such a sceptic the primary and perhaps only task of universities, and those who work there, is the production and transmission of knowledge within disciplinary silos. While the post-apartheid higher education transformation agenda - via the White Paper and the HEQC - has focused on the democratisation and repositioning of higher education institutions so that they might be seen as social institutions, this agenda has done little to shift the perspective of the sceptic who may even appeal to academic freedom to sidestep this agenda. However, over the past decade the transformative project has begun to gain traction within higher education institutions leading to the adoption of vision and mission statements at most higher education institutions which include aims and goals that align research and teaching with social responsiveness and the development of a critical citizenry. Further, recent student led activism - particularly in the form of the \#FeesMustFall protests and \#RhodesMustFall movement-reveals the desire on the part of some engaged students to draw into question the purposes and practices of higher education institutions themselves. Students, and staff, involved in these movements are bringing into question the relationship between 
higher education institutions and the societies in which they are embedded, as well as their responsiveness to the contexts in which they are centrally located. Similarly, what is brought into question by the students themselves is the relevance of what is taught at universities - how students are prepared by the knowledge and skills 'transmitted' to them for life in a South African context, and in what sense graduates are prepared to contribute to the advancement of society after the completion of their degree. For both of these movements the call has been for the suspension of 'business as usual' and the challenging of the status quo, which in the context of post-apartheid South Africa means the perpetuation of deep social, economic, racial and gender inequality. In this article, we will not offer arguments to address the sceptic's concern directly, however we believe that what is currently happening in the context of higher education in South Africa makes the sceptic's position untenable, or, at the very least, unpopular. Given this, in what follows, we will take it for granted that at least one of the goals of higher education (in the South African context) is the development of civic-minded graduates.

A number of strategies could be adopted by universities to achieve this goal. The main tenet of the first strategy is that the transformation of the university space, particularly in terms of its structures and demographics, will increase the ability of the university to foster civic-mindedness in its graduates. The second strategy is based on the idea of implementing transformative teaching and learning practices, while the third centres on implementing community engagement programmes. However, to date, none of these strategies seem to have been particularly effective (Erasmus 2014). In this paper we argue that this failure is, at least in part, due to a lack of epistemic transformation in institutional culture. It is only through an epistemic revolution in institutional culture that universities, we argue, can become spaces that foster the development of civicminded graduates.

\section{UNIVERSITY TRANSFORMATION AND THE DEVELOPMENT OF CIVIC-MINDED GRADUATES}

In this section we explore three plausible suggestions put forward in the literature on how to go about developing civic-minded graduates. These involve transforming institutional culture, as well as engaging in transformative learning practices and the introduction of 'community engagement'. We discuss each suggestion in turn, highlighting why we believe that none of these suggestions on their own have led to the kind of widespread transformation of the sector that we are hoping for.

\section{Transforming the university site}

The goal we have been discussing thus far is the fostering of civic-minded graduates. Another important goal that South African universities have recently set for themselves in their vision and mission statements is institutional transformation. This goal has rarely been discussed in relation to the former goal, although important connections 
should be drawn between the two. When these two goals are brought together a plausible suggestion is that it is through the transformation of 'institutional culture' that both of these goals - institutional transformation and the development of civic-minded graduates - can be achieved.

The transformation of institutional culture, suggested for universities in South Africa, has tended in recent work to focus on transformation in the form of making universities more demographically inclusive and diverse both in terms of students and staff (Soudien 2010), as well as through the 'Africanisation' of university spaces (Metz 2014). Thad Metz (2014) provides us with a clear summary of the various rationales supporting the Africanisation of our universities and argues that the rationales based on redress, civilisation and identity provide the strongest support for the Africanisation of our university spaces. Rationales based on the idea of redress refer to compensation for previous harms done during the Apartheid regime and/or defending Africans from further race-related harm. Rationales based on the idea of civilisation echo sentiments of the so-called 'African Renaissance', where the claim is that African ways of life should be explored 'with the [aim] of revitalising African civilisation' (Metz 2014, 251). Finally, rationales based on identity claims propose that universities in South Africa should be helping African students to understand or 'know' themselves, thereby giving them a sense of pride in who they are. Metz argues that together these three rationales should be taken seriously and given moral weight in the South African context. According to Metz, the Africanisation of our universities should cover the curriculum in terms of teaching African perspectives, indigenous knowledge systems, texts written by Africans, and research, the use of language - both spoken and written - as well as aesthetics and styles of governance.

The assumption at work in these suggestions is that when institutional culture is more inclusive and diversified it provides a learning environment where students are exposed to a myriad of beliefs, values and cultures, which will positively influence them and attune them to the benefits of social diversity experienced within the microcosm of the university campus. Institutional transformation of this kind is important, and the assumption that student experiences of attending universities which have transformed in this sense will lead to a degree of student transformation is at least intuitively plausible. There is widespread consensus across both the social sciences and cognitive science that the situation (comprising the physical and environmental factors as well as the social and political factors) in which we find ourselves plays an important role in the formation of our beliefs, values and identities. If this is so then it is plausible that a transformed university would be more likely to produce suitably transformed graduates.

But, we caution against this conclusion because even when universities have more diverse staff and student bodies, this limited exposure to diversity can have only a minor impact on students' lives. That is, university communities are naturally large communities, which are comprised of a number of sub-communities that students occupy of their own volition. But, it is not obvious that these sub-communities would reflect transformation at the institutional level. It is also not obvious that there is much 
interaction between diverse sub-communities inside the university space. Following this, it is plausible to imagine a student who arrives at university, travels through their undergraduate degree and leaves the hallowed halls of the institution without ever having had any interaction, other than that which is merely superficial, with students from other sub-communities. It is possible that even in a transformed university a student may arrive and leave having only engaged with those from within her own sub-community. As this example illustrates, the Africanisation of our universities, while a plausible and important suggestion, is not necessarily enough to transform students who attend universities in the requisite way. That is, transforming institutional culture in the ways described above cannot by itself produce critically aware engaged citizens who act with a social justice agenda. Despite this, we suggest in what follows that the transformation of institutional culture remains central to the goal of developing civicminded graduates.

According to Tabensky (2014), we should advocate a counter-cultural move that echoes ancient Greek conceptions of the university as a space that fosters both wisdom and virtue. For Tabensky, universities should be in the business of challenging prevalent modes of being and perceiving, which, he argues, act as a lens through which students engage not only with themselves - their ideas, beliefs and values - but also with each other and the societies in which they live. Tabensky's claim is reiterated in the words of Janet Moore (2005), who writes:

An enormous potential exists for universities to be leaders in questioning the status quo, challenging paradigms and openly practicing new ways of living, thinking, teaching, and learning. (Moore 2005, 78)

Countercultural moves of this kind could also, we suggest, help to produce civic-minded graduates.

\section{Transformative teaching and learning}

The claims of Tabensky (2014) and Moore (2005) are also consistent with recent theories of transformational learning - according to which higher education should focus on the transformation of students into autonomous 'change agents'. Jack Mezirow (2000) provides us with one possible way of making sense of transformational learning within higher education. In order to understand his account, we first need to grasp the conceptual landscape within which he is working.

According to Mezirow, we make sense or meaning of our experiences using socially constructed frames of reference, which are divided into 'habits of mind' and 'points of view'.

A habit of mind is a set of assumptions - broad, generalized, orienting predispositions that act as a filter for interpreting the meaning of experience... A habit of mind becomes expressed as a point of view [which] suggest[s] a line of action that we tend to follow automatically unless brought into critical reflection. (Mezirow 2000, 17-18) 
According to Mezirow, the aim of higher education lies in transforming our frames of reference in an attempt to foster autonomy and socially-directed behaviour. However, given his taxonomy, points of view are both easier to access and more amenable to change, and so we need, he argues, to begin with transforming these if we hope to transform our deeper mental habits and, thereby, our overarching frames of reference.

Throughout his work, Mezirow $(1997 ; 2000)$ emphasises the role that critical reflection and dialogue with others play in transforming our frames of reference. He writes:

A sense of agency implies that one can understand perceptively. Such understanding requires the ability and disposition to become critically reflective of one's own assumptions as well as those of others, engage fully and freely in discourse to validate one's beliefs, and effectively take reflective action to implement them...Central to the goal of adult education in democratic societies is the process of helping learners become more aware of the context of their problematic understandings and beliefs, more critically reflective of their assumptions and those of others, more fully and freely engaged in discourse, and more effective in taking action on their reflective judgments. (Mezirow 2000, 25-31)

From this quote we see that engaging in both critical reflection and dialogue, or discourse, with others are central to Mezirow's account of transformative learning, precisely because these activities increase our understanding of our own and others' frames of reference with the ultimate aim of promoting autonomy and behaviour aimed at social justice. As Mezirow writes, '[t]hinking as an autonomous and responsible agent is essential for full citizenship in democracy and for moral decision making in situations of rapid change' (Mezirow 1997, 7). In elucidating his account, Mezirow provides us with a useful distinction between subjective and objective reframing, where the former refers to critically reflecting on and assessing our own beliefs and the latter refers more particularly to reflecting on and assessing matters outside of the self. In elucidating the latter, Mezirow claims that the objective reframing of our beliefs and assumptions takes place when 'reading a book, hearing a point of view, [and] engaging in task-oriented problem solving' (Mezirow 1997, 7). What these activities have in common is engaging with the points of view and frames of reference of other individuals. Importantly, trying on other positions gets us to critically engage with our own, with how our points of view and frames of reference differ or cohere with those of others, 'and [to] arrive at a tentative best judgment regarding contested beliefs' (Mezirow 1997, 9). It also enables one to imagine alternative responses to situations, and, so, makes one better able to work with others to solve problems. ${ }^{1}$ According to Mezirow, then, transformation occurs in both of these ways - through both subjective and objective reframing - which means

1 Becoming critically reflective of the assumptions of others is fundamental to effective collaborative problem posing and solving. Becoming critically reflective of one's own assumptions is the key to transforming one's taken-for-granted frames of reference, an indispensable dimension of learning for adapting to change. 
that 'learning is a social process, and discourse becomes central to making meaning' (Mezirow 1997, 10). ${ }^{2}$

Mezirow's distinction between habits of mind and points of view is particularly helpful for our purposes because it allows us to suggest that the standard pedagogical techniques employed at institutions of higher learning primarily target points of view, and fail to properly transform habits of mind and in turn our overarching frames of reference. What we have problematised in this paper is the very question of whether what students learn at university does transform them on a personal level. In Mezirow's terms, we could say that university education has stopped short of altering habits of mind and so has failed to properly transform students into critically engaged agents for change.

An example is helpful here. Given the prevalence of international corporate scandals in our recent past (for example, at Enron and Tyco), accounting students now have to complete an ethics course in their third year of university. This course aims not only to change the way that these students think about their profession and their role as an accountant, but also aims to prevent the occurrence of fraudulent behaviour by fundamentally changing what motivates these students in relation to ethics and money. Given Mezirow's taxonomy, we are able to argue that what this course needs to do is not just change the points of view of accounting students, but also change their habits of mind and thereby the very frames of reference that they use to make meaning and guide their behaviour. Mezirow's account allows us to say that changing someone's point of view is not enough to transform that person; we need to change their mental habits and frames of reference so that newly formed points of view are not merely overridden by the habits of mind already in place when it comes to acting. Given this, the question now becomes 'how do we directly target mental habits'?

In other work, Mezirow gestures towards various experiential pedagogical methods that have been found useful in transformative education, which include:

participation in social action...These methods encourage critical reflection and experience in discourse. The focus is on discovering the context of ideas and the belief systems that shape the way we think about their sources, nature, and consequences. (Mezirow 2000, 10-11)

While Mezirow has been criticised for not paying enough attention to social action (Moore 2005), we see above the importance of both experience and action to his account, and it is our contention that cashing this out in more detail - in terms of embedding service-learning into the curriculum - could help universities to achieve their goal of developing civic-minded graduates.

2 [our emphasis] This is central to the pragmatist's position, which we discuss later. 


\section{Transformation through community engagement}

According to John Saltmarsh et al. (2009) there is:

widespread agreement that colleges and universities have civic and public purposes, including the preparation of an enlightened and productive citizenry and engaging in scholarship that both addresses pressing problems and holds a mirror to society to allow for self-reflection and selfcorrection. (Saltmarsh et al. 2009, 3)

By and large universities have attempted to address this under the umbrella of 'community engagement', but there is broad dissensus about the theoretical underpinnings and practical implications of community engagement across most institutions in Southern Africa (Erasmus 2014). However, there seems to be consensus about at least one thing: in spite of the emergence of a number of university community engagement activities, 'few institutions have made the significant, sustainable, structural reforms that will result in an academic culture that values community engagement as a core function of the university' (Brukhardt et al. 2004, 5).

One important attempt to institutionalise community engagement in a way which could contribute to the goal of producing civic-minded graduates, and thus be seen as essential to the core functioning of the university, is through the development of institution wide service-learning courses. Traditionally service-learning courses have been conceived of in the following way:

the students' community service experiences...functio[n] as a critical learning complement to the academic goals of the course. In other words, academic service learning is not about the addition of service to learning, but rather the integration of service with learning...[T]he service and the learning are reciprocally related; the service experiences inform and transform the academic learning, and the academic learning informs and transforms the service experience. (Howard 1998, 21-22)

In the South African context the service-learning movement has drawn, to some extent, on this traditional model, in which service-learning is seen as the curricular version of community engagement understood as a form of experiential learning, and has thus largely been infused into universities' teaching and learning practices. However, within the South African context, unlike the North American context, a greater emphasis has been placed on the building of 'mutually-beneficial relationships with various communities in areas of discipline strength and community issues' (Osman \& Petersen 2013,6). This emphasis is particularly noteworthy in light of a more dramatic shift away from earlier service-learning (and community engagement) practices, which were rightly critiqued in their earlier instantiations for reproducing relations of privilege, inequality, and charity-based outreach practices modelled on a deficit approach to community development. These earlier deficit approaches to service-learning have rightly been superseded by models using asset-based approaches to community development in which mutually reciprocal relationships between academic and community partners 
are taken to be essential. The kind of citizenship ideally fostered by service-learning activities under this paradigm is one in which students do not see themselves as saviours of less fortunate communities, but rather as co-protagonists in a mutually beneficial development paradigm in which all parties are seen as equally responsible for, and actively contributing to, human and community development in a co-planned project. ${ }^{3}$

Service-learning, acting both as a pedagogical tool and as a form of community engagement, is consistent with the importance that Mezirow places on participating in social action, and thus could be seen as an important way to produce civic-minded graduates. In service-learning courses students are given 'the responsibility for discerning important from unimportant "data" in the community [which] is contrary to traditional courses in which knowledge is deciphered for the students by the instructor' (Howard 1998, 22-23). Further, service-learning courses provide an enriched platform for experiential learning in that 'for students to respond ethically and academically to learning, they need to engage with others' thinking with a view to forming their own theories...[S]ervice learning...offers students a rich and dynamic pathway to do exactly this' (Osman \& Petersen 2013, 3). The experiential nature of the learning involved in service-learning, then, can be seen as essential for the proper transformation of students. Recall that in the experiential model:

Doing is more important than knowing. Knowledge is no longer perceived to be the ultimate goal (the half-life of information is so short). Results and actions are considered more important than the accumulation of facts. (Oblinger 2003, 40)

Unlike experiential learning, service-learning courses explicitly emphasise the advancement of a 'student's sense of social responsibility or commitment to the broader good' (Howard 1998, 24). While 'the nature of the traditional classroom encourages individual responsibility rather than social responsibility' (Howard 1998, 24), service-learning courses can be seen to raise the pedagogical bar through insisting on 'advancing [the] student's commitment to the greater good' (Howard 1998, 24). What has the potential to set the South African service-learning tradition apart from the North American service-learning tradition is its possible responsiveness to the transformation context of South African higher education, particularly with respect to its focus on the notion of service-learning as social change. As Osman and Petersen (2013) put it:

We believe that service learning with an eye to social change can open up a space where students are not simply socialised into the dominant hegemonic practices of their disciplinary field... [W]e also believe that service learning as social change has the potential to direct students' transformative learning experiences. (Osman \& Petersen 2013, 12)

Despite the potential of service-learning to produce socially-responsive agents of change, community engagement activities in the form of volunteerism are still dominant in the higher education sector in South Africa. Furthermore, while voluntary community

3 See for instance Mathie and Cunningham 2005; Donaldson and Daughtery 2011; Artz 2001. 
engagement activities could serve to enhance students' sense of social responsibility and so help universities to achieve their goal of developing civic-minded graduates, such activities do little to shift students' perceptions about the goals of academic learning. In contrast, institutionalising service-learning courses could do more to shift students' perceptions about the goals of academic learning and the core functions of the university, primarily because the curriculum tacitly informs students about what is important or legitimate in their university education and thus informs students' perceptions about what the university believes it is important for them to learn. Service-learning legitimises community engagement activities in such a way that they are no longer seen as "nice-tohave add-ons' but rather as central to the purpose of attending university.

However, while a strategy that embraces community engagement activities is the most plausible of the three suggestions we have discussed - since it combines transformative learning with experiential learning in the community, it hasn't been seen to have the kind of impact that we might expect it to have on either developing civicminded graduates or altering perceptions of the core functions of the university. But if this is the most plausible suggestion, then could there perhaps be systemic universitywide problems that are preventing this strategy from succeeding?

\section{INSTITUTIONAL CULTURE AND THE EPISTEMOLOGICAL PROJECT OF THE UNIVERSITY}

In this final section we examine various limiting factors that could be preventing community engagement activities from doing the kind of transformative work we expect. These factors include (1) the dissensus among universities about the nature, purpose and implementation of community engagement activities, (2) a lack of funding from government for these activities, and (3) the particular socio-historical and material context in which South African universities operate (including the global neo-liberal ethos). In what follows we will discuss each in turn, showing how they are interrelated and compound one another, while also operating to reinforce non-transformative and recalcitrant epistemic paradigms and practices that prevent community engagement practices from having the transformative effect we might have imagined them to have had. In doing so we take into consideration the underlying epistemological frameworks and paradigms governing higher education institutions, which inform both the ways in which academics come to see themselves and their role in the production and dissemination of knowledge. Ultimately we will argue that it is only through an epistemological shift in institutional culture that these activities could come to have the transformative effect that we desire.

At a global level we find among universities dissensus concerning the nature, implementation and purpose of community engagement activities. Indeed, this problem has been discussed in the literature on community engagement more broadly, and on service-learning in particular. For example, Goodwin Liu (2000) suggests: 
It is tempting to believe that service-learning is reshaping our understanding of education in important and dramatic ways. Yet practice still varies considerably at the program level, and we continue to struggle for a definition of service-learning that is capable of eliciting broad consensus and usage in the field. As a consequence, service-learning has appeared to lack rigor, and [has] failed to penetrate mainstream educational practice on most campuses. (Liu 2000, 24)

Moreover, while this is a problem at the global level it is reflected in quite particular ways in the South African context. The post-apartheid paradigm, that is, seems to provide a platform for higher education institutions to respond to and engage with external stakeholders and local communities in 'respectful' and 'humble' ways in an effort to redefine themselves in opposition to their former identity as separatist, colonial, privileged beacons of the Apartheid regime. However, mirroring the global trend, community engagement within the South African higher education sector has been met with resistance and has largely been regarded as a left-wing and radical movement that is seen to detract from the primary purposes of higher education institutions. That is, the purpose of these activities is often misunderstood by academics on the ground leading to 'limited unequivocal support for community engagement' (Erasmus 2014, 105) on the part of academics.

One of the major stumbling blocks to a proper understanding of the nature and purpose of community engagement is that the dominant models of community engagement currently being implemented in universities have focused on the importance of activities occurring in a particular space, namely 'the community', and consequently community engagement has been seen by universities to incorporate a range of activities that occur in the community, encompassing volunteering, outreach programmes, service-learning and engaged research. In the Democratic White Paper, Saltmarsh et al. question, then, whether community engagement efforts are transforming higher education, or whether community engagement efforts have merely been 'adopted in ways that do not fundamentally challenge the dominant cultures of higher education institutions' (Saltmarsh et al. 2009, 1). The umbrella approach to community engagement at universities has led to such activities being adopted and incorporated into 'the existing cultures of higher education [without calling] for changes in ways colleges and universities fundamentally operate - in underlying assumptions and institutional behaviours, processes, and products' (Saltmarsh et al. 2009, 6). Following John Dewey, they argue that it is only through service-learning and by practising democracy and social justice as part of the university educational experience that students can be thought to graduate from university with the transformative attributes that universities aim to impart to their graduates, saying that what needs to be emphasised

is the meaning of democracy in an educational setting - not that it is merely the university's inspirational role to prepare students for civic responsibility after they graduate, but that through their educational experience students experiment with and practice democracy through their community based educational experiences. (Saltmarsh et al. 2009, 2-3) 
What Saltmarsh et al. argue is that community engagement practices at university must themselves be democratic. Furthermore, they gesture towards the idea that, in the process of becoming democratic, engagement activities must challenge the dominant epistemic practices that govern them. They explain that in the traditional epistemological model

knowledge produced by credentialed detached experts is embedded in hierarchies of knowledge generation and knowledge use, creating a division between knowledge producers (in the university) and knowledge consumers (in the community). In this scheme, 'researchers "produce" knowledge, which is then "applied" to problems and problematic populations'... academic knowledge is valued more than community-based knowledge, and knowledge flows in one direction, from inside the boundaries of the university outward to its place of need and application in the community. (Saltmarsh et al. 2009, 7-8)

They argue, we think rightly, that without making the shift away from this dominant epistemological framework, community engagement activities cannot truly provide spaces for students to gain experiential knowledge of the democratic process or of social justice:

Without a democratic purpose, engagement efforts are often pursued as ends in themselves, and engagement becomes reduced to a public relations function of making known what the campus is doing for the community and providing opportunities for students to have experience in the community. Engagement in this sense reflects the dominant academic culture of higher education, often characterized as 'scientific', 'rationalized', 'objectified', or 'technocratic', meaning that the approach to public problems is predominantly shaped by specialized expertise 'applied' externally 'to' or 'on' the community, providing 'solutions' to what has been determined to be the community's 'need'. (Saltmarsh et al. 2009, 6-7)

They explain that community engagement activities at universities, which mirror this kind of dominant epistemology, remain only of limited use or effectiveness in helping universities to foster civic-minded graduates.

What can be derived from this discussion is that a misunderstanding of the nature of community engagement - a misunderstanding informed by the dominant epistemic paradigm - leads directly to an ambiguity in terms of the purpose of these activities. This leads to the further question of how community engagement activities further or bolster the knowledge project of our universities, which itself seems to be a contested area. Ultimately, if academic institutions and academics themselves do not understand how community engagement activities further the knowledge production project, then there will inevitably be resistance to embracing the epistemic shift required for transformative community engagement practice.

This misunderstanding of the nature, purpose and implementation of community engagement activities is further compounded by a lack of funding for these activities. As noted by Erasmus: 
Another limiting factor in the implementation of community engagement initiatives is the fact that it has not (yet) been funded by government and thus remains an 'unfunded mandate'. (Erasmus 2014, 106)

The lack of funding allocated to community engagement activities has led to the unavailability of resources - both human and physical - needed to properly implement initiatives which might be seen to further teaching and research engagement strategies. Again, this has led to confusion in terms of the purpose and aims of community engagement in the higher education sector, since, under these conditions, community engagement in the form of volunteerism seems to flourish, while strategies aimed at the development of transformative learning pedagogies, such as service-learning and engaged research, ${ }^{4}$ tend to remain underdeveloped. The implicit message conveyed by the state to academic institutions and academics themselves is misleading insofar as it mandates a number of things that universities ought to do while at the same time the funding it offers legitimises only certain of these activities. ${ }^{5}$ In the case of community engagement the lack of funding delegitimises this mandate. Just as with service-learning, where the service activity is legitimised by being credit bearing in the eyes of students, so too community engagement would be legitimised in the eyes of the institution and its academics if it were a funded rather than unfunded mandate from government. As Erasmus points out, until funding has materialised for community engagement 'governments' community engagement and transformation "narrative" could be regarded as a "socially symbolic act" that could have little impact on the actual nature and functioning of higher education institutions' (Erasmus 2014, 107). This ambiguity could explain the reticence of academics to challenge what Saltmarsh et al. refer to as the dominant epistemic practices that govern the kind of community engagement activities which emerge within the current unfunded mandate of government, as discussed above.

Under the influence of neo-liberal and market forces the global higher education sector has undergone massive transformations in terms of its overarching goals, norms and values. Moving away from a primary focus on knowledge production, we have seen a massification of the higher education sector in an attempt to produce skilled labourers for the market, which has simultaneously served the goal of beginning to undermine the

4 Engaged research presents a methodological approach that recontextualises and challenges traditional positive research and allows for the co-creation of knowledge in ways that are mutually beneficial both to the communities in which the research is carried out and to those carrying out the research. Engaged research represents a shift to a more collaborative and inclusive approach to knowledge generation and dissemination, which is intentionally adopted by researchers in order to harness the assets available in the communities in which research is being carried out and so further the research goals and outputs of academic projects through collaboration (Paphitis \& Kelland 2015).

5 Of course we can challenge to what extent the state ought to have any influence over the academic project simpliciter, however, given the current mandates by the state and the concurrent funding streams, it remains legitimate to ask about the influence of these mandates and funding streams over the choices of academics and institutions in terms of the pedagogical practices, research topics and their roles in society. 
elitism associated with higher education, exemplified in the idea of the university as an ivory tower. We have also seen the restructuring of universities' faculties, departments, and programmes to be more responsive to the needs of the market and the economy in general, which has meant that external stakeholders - such as business enterprises, employers, and the state - have come to exert more of an influence over the internal structures, curriculum, and 'knowledge' produced and disseminated by universities - ultimately these now aim, to some degree, to prepare graduates for the workplace (Ntshoe 2004). At the same time, we have seen a massive movement in the higher education sector globally towards the recognition of a second external stakeholder namely the broader public. That is, the higher education sector has undergone a further transformation in terms of its aims and goals, which are now also thought to include the development of graduates who are socially aware and who are active citizens guided by the principles of social justice (Erasmus 2014). This has played itself out in the higher education sector primarily through the development, on the one hand, of servicelearning and volunteerism activities, in which students are involved in communitybased or citizenship activities, and, on the other, of job-readiness activities in which students are trained for the market.

The South African higher education sector has similarly been subject to the force of a neo-liberal ethos. However, the end of apartheid and the transition to a democratic state have played a major role in shaping how we think about transformation within this sector locally. The post-apartheid moment, that is, has provided the higher education sector in South Africa with the opportunity to reflect on the goals of higher education within its particular context. Considering transformation in the higher education sector of post-apartheid South Africa should include considerations of equity, redress, social justice, development, the decolonisation of the curriculum and institutions themselves, as well as a reintegration of higher education institutions into the new democratic social fabric of the country; all of which create a particular socio-historical milieu in which higher education transformation takes shape in the particular context in which South African HEIs operate. However, according to Erasmus,

Literature suggests that after almost two decades of 'higher education transformation' in South Africa, key elements of what such transformation set out to achieve have not shown as much progress as might be expected. (Erasmus 2014, 105)

One reason for the lack of progress of transformation in the South African higher education sector is the prevalence of a kind of institutional schizophrenia within the sector itself, where, on the one hand, universities strive to serve the interests of global neo-liberal market forces while, on the other, striving to serve the interests of the local public good through being 'more engaged with local constituencies and more responsive to the challenges faced by the various communities with which they interact' (Erasmus 2014, 102). While it might sound plausible to at the same time prepare students for the workplace and foster in them a sense of civic duty, when we translate this into university 
goals it becomes less obvious to think of the university as simultaneously serving both the interests of neo-liberal market forces and the public good. As Ntshoe puts it:

After apartheid [Higher Learning Institutions], as the public sector more generally, have been driven by the contradictory imperatives of social justice (to improve equity and access) and the requirements of neo-liberalism (to serve the economy and markets and the internal demands of their disciplines). (Ntshoe 2004, 211-212, our emphasis)

Following this strand of thought, Tabensky (2014) bemoans the fact that universities have primarily come to be places where students are capacitated to become professionals who are able to enter the marketplace and reproduce the status quo. The simultaneous reproduction of the status quo, which is tied to a neo-liberal ethos, and the attempt to produce civic-minded graduates cuts to the heart of the institutional schizophrenia that characterises higher education institutions today. That is, particularly in the postapartheid South African context, attaining social justice stands in direct contradiction to a neo-liberal status quo, precisely because social justice in South Africa requires redress, while neo-liberalism - in serving capitalism - does not easily lend itself towards the goal of redress. While corporates may desire agents of the status quo because this serves their purposes, universities need to ask themselves who they are serving - corporates or the public good? - as we cannot, at least not obviously, develop graduates who both reproduce the status quo and serve the public good. In order to remake South African society we cannot go about 'business as usual', rather we must develop students who are agents of change and not agents of the status quo.

The institutional schizophrenia in the higher education sector translates into a kind of ambiguity, initially in the question of what it is that we are educating students for, and subsequently in students' perceptions of why it is that they are attending university in the first place. Working in the higher education sector has provided us with anecdotal evidence of this ambiguity - students are often found questioning how they will use their university education to get a job after leaving university and/or questioning the relevance of what they are taught to the issues facing them in the South African context. While we might bemoan the corporatisation of universities, as Tabensky does, we cannot ignore the fact that, for a lot of students, particularly South African students from previously disadvantaged backgrounds, coming to university and getting a degree is often a means to an end - that is, a means to getting a job, making a good salary and improving one's lot in life in very material ways. In our context, then, it still remains important for the higher education sector to prepare a workforce for the transforming South African society; higher education certainly has a role to play in diversifying this workforce and thereby the South African economy. Despite the fact that students often perceive a university education as primarily important for improving one's job prospects, it nevertheless remains an important goal of the higher education sector to produce graduates who are critically aware and have an enhanced sense of civic responsibility. This is true not only because it is essential for the proper transformation of the sector to 
take place but also because it is essential if universities are to produce graduates who do not reproduce but rather subvert and redefine the status quo in line with the principles of equity, redress and social justice. Particularly in the post-apartheid South African context, this important function of the university cannot be ignored. Following Soudien (2010),

[The university] is supposed to be a space of intense self-refection and critique. In this sense it really cannot look like the society in which it finds itself...It has to offer a way forward in modelling for society what it means to be thinking and acting in the public good in ways that exceed party political imaginations. The citizen of the university needs to be guided by this special sense of mission and identity. (Soudien 2010, 234)

Given that community engagement, particularly in the form of service-learning, offers precisely what Jeffrey Howard calls a 'counternormative pedagogy' and what Osman and Petersen call 'service-learning as social change', it would, following the arguments above, allow for universities to produce graduates who are active citizens working in the interests of the public good, rather than graduates who merely reproduce the status quo.

While all three factors go some way towards explaining the failure of community engagement activities to have the desired wide-scale transformative effect we might have expected them to have, we cannot properly make sense of this failure without recognising the underlying role of the epistemic. All three factors, in some way, reinforce the dominant epistemic paradigm governing higher education institutions, and so, putting into practice community engagement activities that follow the kind of counternormative pedagogy suggested by Howard, which would require precisely the kind of epistemic shift suggested by Saltmarsh et al., are typically neglected by academics who find these kinds of pedagogies 'unsettling' (Osman \& Petersen 2013, 12) and/or unnecessary. According to Howard, in service-learning an intentional effort is made to

utilize the community-based learning on behalf of academic learning and to utilize academic learning to inform the community service. This presupposes that academic service-learning will not happen unless a concerted effort is made to harvest community-based learning and strategically bridge it with academic learning. (Howard 1998, 22, our emphasis)

As a result of this, he argues, service-learning faces a number of challenges in being adopted campus wide that result from its counter-normative nature in this epistemic respect. Liu brings the point home in his paper 'Knowledge, Foundations, and Discourse: Philosophical Support for Service-Learning' when he says

For the most part, we have been making arguments for a change in pedagogy without the support of arguments for a change in epistemology...education takes place within an epistemological frame: If we wish to rethink the way we teach and learn, then we need to rethink the way we know. (Liu 2000, 24) 
We endorse the suggestions made by Howard and Saltmarsh et al. above, however, while these scholars are concerned with promoting an epistemic shift within community engagement practices themselves, we argue, more broadly, that this shift must be made at the level of institutional culture. It is not only when planning and conducting community engagement activities that we need to take into consideration the counternormative move advocated by Howard, rather, we need to critically examine how we think about knowledge production and dissemination, as well as our relationship with, and role within, society in relation to the functioning of the university as a whole. In what follows, then, we gesture towards what this kind of epistemic shift in institutional culture would look like by drawing on an international example. Importantly, it is not our suggestion that South African institutions should follow this example in order to emulate it wholesale; rather, our suggestion is that the way in which the epistemic shift is embodied in this example could be used as a point of departure for rethinking and remaking the knowledge project in our own institutions and contexts.

In his final essay, Isaiah Berlin explains the epistemic monism underpinning institutional culture, which was problematised in the previous section, as follows:

The enemy of pluralism is monism - the ancient belief that there is a single harmony of truths into which everything, if it is genuine, in the end must fit. The consequence of this belief...is that those who know should command those who do not. Those who know the answers to some of the great problems of mankind must be obeyed, for they alone know how society should be organized, how individual lives should be lived, how culture should be developed. This is the old Platonic belief in the philosopher-kings, who were entitled to give orders to others. There have always been thinkers who hold that if only scientists, or scientifically trained persons, could be put in charge of things, the world would be vastly improved. To this I have to say that no better excuse, or even reason, has ever been propounded for unlimited despotism on the part of an elite which robs the majority of its essential liberties. (Berlin 1998)

We believe, as suggested by Berlin, that such a shift would move away from the monist model, in which academics and universities are seen as the 'producers' of knowledge, while those outside the walls of the academy - those in the 'community'-are seen as the 'consumers' of knowledge, to a model which embraces pluralism and embodies democratic praxis. The move towards pluralism suggested by Berlin is consistent with the form of pragmatism advocated by Liu, which allows us to understand knowledge as found somewhere on the gradient between the extremes of absolutism and relativism. Following the framework of Richard Rorty's Philosophy and the Mirror of Nature, Liu argues, like Berlin, that

Individuals in isolation are not entitled to legitimize knowledge; that function is reserved for communities in which truth claims are continually tested and contested in the context of discourse. (Liu 2000, 38)

And, further he argues that 
Philosophically, we locate this middle by understanding knowledge in the context of conversation; pedagogically we find it by putting teaching and learning in the context of community. (Liu 2000, 38)

According to Liu, shifts in epistemic commitments of this kind will transform universities in terms of their pedagogical function, saying:

From this epistemology, community emerges as a critical pedagogical virtue. It is a precondition of learning in two senses: First, community is the place where discourse occurs, and second, community is the ethic that enables discourse to occur. If discourse is what makes knowing possible...then community is what makes learning possible in educational institutions where thinking alone is still the norm. (Liu 2000,38, our emphasis)

While Lui focuses here on the goals of teaching and learning, the epistemic shift suggested would also have important implications for research and for the relationship between the university and the broader public.

Recall that for Saltmarsh et al. there is 'widespread agreement that colleges and universities have civic and public purposes... and [should hold] a mirror to society to allow for self-reflection and self-correction' (Saltmarsh et al. 2009, 3). This goal of the university will also require the kind of epistemic shift suggested by Howard, Saltmarsh et al., Liu, and Berlin.

The nature of this epistemic shift is also explored by Ira Harkavy and Lee Benson (1998) through their discussion of Seth Low's term of presidency at Columbia College in which he embraced an epistemic shift at the level of institutional culture. They argue that by embracing New York City as 'the source of the University's greatness', he 'brought the College into closer touch with the community' (Harkavy \& Benson 1998, 14). They say

No other university president had so clearly articulated a morally inspired, instrumental, active approach to research, teaching, and learning. In effect, repudiating Plato's notion of the groves of academe with its physical and intellectual separation of town and gown, Low linked town and gown, identifying a mutually beneficial, interactive relationship between Columbia and the city as crucial to intellectual and institutional advancement... In Low's case, the specific test was Columbia's ability 'to influence the life of New York'. That influence would not result, moreover, from the authoritative, elitist, university-dominated approach advocated by many of the most 'progressive' Progressive-era academics. To the contrary, Low's approach was decidedly democratic in dealing with the city and its people. Learning would be, he emphasized, reciprocal and interactive: 'Workingmen of America...[should know] that at Columbia College...the disposition exists to teach the truth... without fear or favour, and we ask their aid to enable us to see the truth as it appears to them'. (Harkavy \& Benson 1998, 15)

What is notable about this example is not only that Low made the epistemic shift outlined above, but that in making this shift part of Columbia's institutional culture, Columbia not only became a beacon of community engagement, but a formidable research institution as well. Harkavy and Benson argue that Seth Low 'also significantly 
improved Columbia [as an academic institution] by successfully encouraging faculty and students to focus their intellectual work on helping New York solve its problems' (Harkavy \& Benson 1998, 14).

It is likely then, we suggest here, that it is by embracing this epistemic shift at the level of institutional culture that transformation could run deep enough to affect the three core pillars of the university (teaching and learning, research and community engagement), enabling universities to achieve the goal of developing civic-minded graduates, and making universities spaces for transformation rather than merely transformed spaces, in the eyes of both their students and the broader public. One of the most significant barriers to the widespread adoption of the proposed epistemic shift in institutional culture is a reticence on the part of the academy to let go of its own privileged position as the 'rightful' and sole home of knowledge production and dissemination. Like many other revolutions, the epistemic revolution, we suggest, will only begin to gain momentum through building a critical mass of supporters. Individual academics who have embraced the epistemic shift must lead by example in order to dispel the misconception that the twenty-first century university can continue to operate as an ivory tower.

\section{REFERENCES}

Artz, L. 2001. Critical ethnography for communication studies: Dialogue and social justice in servicelearning. Southern Communication Journal 66(3): 239-250.

Berlin, I. 1998. The first and the last. New York Review of Books, 45(8). Retrieved from: http://www. cs.utexas.edu/users/vl/notes/berlin.html (accessed 25 May 2014).

Brukardt, M.J., B. Holland, S. Percy, and N. Zimpher. 2004. Calling the question: Is higher education ready to commit to community engagement? A Wingspread statement 2004. Retrieved from: http://www.uwm.edu/MilwaukeeIdea/elements/wingspread.pdf (accessed 27 May 2014).

Donaldson, L. and L. Daughtery. 2011. Introducing asset-based models of social justice into service learning: A social work approach. Journal of Community Practice 19(1): 80-99.

Erasmus, M. 2014. The political unconscious of higher education community engagement in South Africa. In Knowledge as enablement: Engagement between higher education and the third sector in South Africa. Edited by M. Erasmus and R. Albertyn, 100-118. Bloemfontein: Sun Press.

Harkavy, I and L. Benson. 1998. De-Platonizing and democratizing education as the basis of service learning. New Directions for Teaching and Learning 73: 11-20.

Howard, J. 1998. Academic service learning: A counternormative pedagogy. New Directions for Teaching and Learning 73: 21-29.

Janse van Rensburg, E. 2014. Enablement - a foundation for community engagement through service learning in higher education. In Knowledge as enablement: Engagement between higher education and the third sector in South Africa. Edited by M. Erasmus and R. Albertyn, 41-61. Bloemfontein: Sun Press. 
Liu, G. 2000. Knowledge, foundations, and discourse: Philosophical support for service learning. In Beyond the tower: Concepts and models for service learning in philosophy. Edited by D. Lisman and E.I. Harvey. USA: American Association for Higher Education.

Mathie, A. and G. Cunningham. 2005. Who is driving development? Reflections on the transformative potential of asset-based community development. Canadian Journal of Development Studies 26(1): 175-186.

Metz, T. 2014. Africanising institutional culture: What is possible and plausible. In Being at 'home': Race, institutional culture and transformation at South African higher education institutions. Edited by S. Matthews and P. Tabensky, 242-272. Durban: UKZN Press.

Mezirow, J. 1997. Transformative learning: Theory to practice. New Directions for Adult and Continuing Education 74: 5-12.

Mezirow, J. 2000. Learning to think like an adult: Core concepts of transformation theory. In Learning as transformation: Critical perspectives on a theory in progress. Edited by J. Mezirow, 3-33. Jossey Bass: John Wiley and Sons.

Moore, J. 2005. Is higher education ready for transformative learning: A question explored in the study of sustainability. Journal of Transformative Education 3(1): 76-91.

Ntshoe, I. 2004. The politics and economics of postapartheid higher education transformation. Comparative Education Review 48(2): 202-221.

Oblinger, D. 2003. Boomers, gen-xers and millenials: Understanding the new students. Educause Review, January 1, 2003. Retrieved from: http://www.educause.edu/ero/article/boomers-genxers-and-millennials-understanding-new-students (accessed 22 May 2014).

Osman, R. and N. Petersen. 2013. An introduction to service learning in South Africa. In Service learning in South Africa. Edited by N. Petersen and R. Osman, 2-32. Oxford and New York: Oxford University Press Southern Africa.

Paphitis, S. and L. Kelland. 2015. Challenging the dominant ideological paradigm: Can community engagement contribute to the central epistemic aims of philosophy? South African Journal of Philosophy 34(4): 419-432.

Saltmarsh, J., M. Hartley and P.H. Clayton. 2009. Democratic engagement white paper. Boston, MA: New England Resource Center for Higher Education. Retrieved from: http://www.ncat.edu/ research/civic-engagement/nerche-paper.pdf (accessed 22 May 2014).

Soudien, C. 2010. Some issues in affirmative action in higher education in South Africa. The South African Journal of Higher Education 24(2): 224-237.

Tabensky, P. 2014. The countercultural university. In Being at 'home': Race, institutional culture and transformation at South African higher education institutions. Edited by S. Matthews and P. Tabensky, 221-241. Durban: UKZN Press. 